\title{
BMJ Open Health system reforms, violence against doctors and job satisfaction in the medical profession: a cross-sectional survey in Zhejiang Province, Eastern China
}

\author{
Dan Wu, ${ }^{1}$ Yun Wang, ${ }^{2}$ Kwok Fai Lam, ${ }^{3}$ Therese Hesketh ${ }^{4}$
}

To cite: Wu D, Wang Y, Lam KF, et al. Health system reforms, violence against doctors and job satisfaction in the medical profession: a cross-sectional survey in Zhejiang Province, Eastern China. BMJ Open 2014;4: e006431. doi:10.1136/ bmjopen-2014-006431

- Prepublication history for this paper is available online. To view these files please visit the journal online (http://dx.doi.org/10.1136/ bmjopen-2014-006431).

Received 20 August 2014 Revised 2 December 2014 Accepted 5 December 2014

CrossMark

For numbered affiliations see end of article.

Correspondence to Professor Therese Hesketh; t.hesketh@ich.ucl.ac.uk

\section{ABSTRACT}

Objective: To explore the factors influencing doctors' job satisfaction and morale in China, in the context of the ongoing health system reforms and the deteriorating doctor-patient relationship.

Design: Cross-sectional survey using self-completion questionnaires.

Study setting: The survey was conducted from March to May 2012 among doctors at the provincial, county and primary care levels in Zhejiang Province, China.

Results: The questionnaire was completed by 202 doctors. Factors which contributed most to low job satisfaction were low income and long working hours. Provincial level doctors were most dissatisfied while primary care doctors were the least dissatisfied. Three per cent of doctors at high-level hospitals and $27 \%$ of those in primary care were satisfied with the salary. Only $7 \%$ at high-level hospitals were satisfied with the work hours, compared to $43 \%$ in primary care. Less than $10 \%$ at high levels were satisfied with the amount of paid vacation time (3\%) and paid sick leave (5\%), compared with $38 \%$ and $41 \%$, respectively, in primary care. Overall, $87 \%$ reported that patients were more likely to sue and that patient violence against doctors was increasing. Only $4.5 \%$ wanted their children to be doctors. Of those 125 who provided a reason, $34 \%$ said poor pay, $17 \%$ said it was a high-risk profession, and 9\% expressed concerns about personal insecurity or patient violence.

Conclusions: Doctors have low job satisfaction overall. Recruitment and retention of doctors have become major challenges for the Chinese health system. Measures must be taken to address this, in order to ensure recruitment and retention of doctors in the future. These measures must first include reduction of doctors' workload, especially at provincial hospitals, partly through incentivisation of appropriate utilisation of primary care, increase in doctors' salary and more effective measures to tackle patient violence against doctors.

\section{INTRODUCTION}

The Chinese medical profession is facing serious problems with the recruitment and

\section{Strengths and limitations of this study}

- Our study is one of the first to investigate doctors' job satisfaction in China since the instigation of the health reforms in 2009.

- We compared doctors' job satisfaction across three levels of health facility and explored associated systemic factors.

- Our study documents for the first time that increasing patient violence is a major contributor to doctors' low morale.

- The generalisability of the study is constrained by the limited number of participating health facilities and the small sample size.

retention of doctors. Evidence from a number of sources illustrates low levels of morale in the profession. In a study of 933 doctors in 29 public hospitals in Shandong province, $49 \%$ said they intended to leave the profession. ${ }^{1}$ Other studies have shown that only $24 \%$ of doctors would choose the profession if they had a second chance ${ }^{2}$ and $78 \%$ would not want their own children to be doctors. ${ }^{3}$ At Shanghai Jiao Tong University, which is among the top five in the country, $10 \%$ of the second year medical students transferred to other majors in $2013 .^{4}$ These worrying manifestations of discontent come at a time when more doctors are needed, given the pressures of an ageing population ${ }^{5}$ and a growing non-communicable diseases burden. $^{6}$ Recruitment and retention of doctors have become major challenges for the health system in China. ${ }^{7}$

There is evidence that this situation is worsening, ${ }^{8}$ so urgent measures are needed to reverse this trend. Clearly, such measures need to include addressing the underlying causes of this discontent. The aim of this study was to explore these underlying causes 
by surveying the views of doctors working at three levels of the health system: tertiary, secondary and primary care. Primary level facilities are supposed to provide preventive and basic medical services, while secondary and tertiary hospitals provide specialised care. The study was conducted in 2012, 3 years after the inception of major health system reforms, aiming to provide universal healthcare by 2020 with a focus on strengthening primary care. The reforms have also had impacts on doctors' working conditions: changes to health insurance have made healthcare more affordable at all levels, resulting in an increased workload for doctors, especially at the secondary and tertiary level hospitals, even for minor illness. The introduction of an essential drug list for primary care, which aims to reduce perverse incentives for overprescribing to forbid profit on drugs, has reduced doctors' autonomy and reduced their income. ${ }^{9}$ This loss of income from the mark-up in primary care has been replaced with a fixed salary and, in some places, a performance-based bonus, which in most cases is lower than previous earnings. ${ }^{10}$

Another important contributor to morale is the recent deterioration in the doctor-patient relationship. ${ }^{11}$ The most extreme manifestation of this is a rise in levels of violence against health workers, along with damage and disturbance to health facilities. In China, this phenomenon is known as $\mathrm{Yi} \mathrm{Nao,} \mathrm{which} \mathrm{translates} \mathrm{as} \mathrm{medical} \mathrm{or}$ hospital disturbance. This is usually caused by patients or their relatives as a reaction to what may be perceived, rightly or wrongly, as failures or mistakes by hospital staff. Sometimes the situation escalates with aggrieved patients and relatives hiring criminal gangs, prepared to go to extreme lengths, to threaten the hospital to provide compensation. ${ }^{12} \mathrm{Yi}$ Nao events are not rare. The Ministry of Health reported that the number of 'major disturbances' involving physical violence nearly doubled from 9831 in 2006 to 17243 in $2010 .{ }^{13}$ In a 2006 study of 270 hospitals, over $70 \%$ reported that they had experienced Yi Nao incidents. ${ }^{14}$ A study of 12 hospitals in 2009 revealed that, of 2464 medical professionals, $50 \%$ experienced workplace violence over the past 12 months, with $20 \%$ encountering physical abuse at least once. ${ }^{15}$ A 2012 survey conducted by the Chinese Hospital Association in 316 public hospitals in 30 provinces revealed that the proportion of hospitals which reported incidents of physical violence causing harmhad increased from $48 \%$ in 2008 to $64 \%$ in 2012. Of these, $8 \%$ of hospitals reported six or more incidents of physical violence every year. ${ }^{16}$ Violence against health personnel is not unique to China. It has been reported from many other countries, including countries as diverse as the UK, the USA, Italy, Saudi Arabia, Pakistan and Japan. ${ }^{17-25}$ Many other countries are facing challenges with the recruitment and retention of doctors. ${ }^{26}$ Therefore, lessons from the Chinese experience are relevant for other countries.

The overall objectives of this study were: (1) to explore the factors influencing doctors' job satisfaction and morale, with a special focus on the impacts of health system reforms and the deteriorating doctorpatient relationship, and (2) to compare doctors working at the three levels in the Chinese health system.

\section{METHODS}

\section{Sampling and data collection}

This cross-sectional survey was conducted from March to May 2012 in health facilities in Zhejiang province, Eastern China. Zhejiang has a population of 55 million and is ranked fourth in terms of GDP per capita among China's 33 provinces.

A multistage stratified purposive sampling method was adopted (table 1). We first selected four cities or counties which represented high-level (Hangzhou and Yiwu), middle-level (Anji) and low-level (Xianju) economic development in Zhejiang province. In the second stage, 10 health facilities were purposively sampled in the four cities/counties to represent a range of health facilities: in urban areas, a multispecialism provincial hospital (tertiary level) in Hangzhou, the main county hospitals (secondary level) in Anji and Xianju, respectively, and two community health centres (CHCs)/township health centres (THCs) (providers of primary care in urban and rural areas) in each city/county were invited to participate (one in Xianju county refused). In total, four CHCs in urban cities and three THCs in rural counties were selected based on their general representativeness in the city/county.

At provincial level hospitals and county hospitals, participants were internal medical doctors and surgeons, who

Table 1 Sampling strategy and achieved sample size by area

\begin{tabular}{|c|c|c|c|c|}
\hline Cities & Income level & Participating hospitals & Sample size & Total sample size \\
\hline \multirow[t]{2}{*}{ Hangzhou } & High income & 1 provincial hospital & 48 & 60 \\
\hline & & $2 \mathrm{CHCs}$ & 12 & \\
\hline Yiwu & High income & $2 \mathrm{CHCs}$ & 54 & 54 \\
\hline \multirow[t]{2}{*}{ Anji } & Middle income & 1 county hospital & 24 & 41 \\
\hline & & 2 THCs & 17 & \\
\hline \multirow{2}{*}{ Xianju } & Low income & 1 county hospital & 19 & 47 \\
\hline & & $1 \mathrm{THC}$ & 28 & \\
\hline Total & & 10 & & 202 \\
\hline
\end{tabular}


were present in inpatient wards at the time of the survey. At CHCs and THCs, primary care physicians present in clinics at the time of the survey were recruited.

Prospective participants were told that the questionnaire was about job satisfaction, that completion was voluntary, and that respondent anonymity and confidentiality would be strictly protected.

\section{Measurement methods}

We developed the questionnaire based partly on existing questionnaires ${ }^{27-30}$ with some items added and modified to specifically reflect the Chinese setting. Most questions used a five-point Likert scale ranging from 1 (not satisfied at all or strongly disagree) to 5 (extremely satisfied or strongly agree). The questionnaire included items about job satisfaction in general, perceptions about patients' health seeking behaviours and experience of patient aggression. Reverse scoring was used for questions phrased in the negative. The questionnaire was piloted, and modifications were made according to the feedback.

\section{Statistical analysis}

The data were analysed using IBM SPSS V.21. Comparisons between three levels of facility were conducted using $\chi^{2}$ tests. We generated an overall job satisfaction score by computing the mean of 19 satisfaction items. The satisfaction score ranges from 1 (the lowest satisfaction) to 5 (the highest satisfaction). A higher score means a higher satisfaction level. Analysis of covariance (ANCOVA) was performed to compare satisfaction scores by levels of response of associated factors controlling for gender, age and education.

\section{RESULTS}

\section{Sample characteristics}

Characteristics of the study sample are shown in table 2. Two hundred and two doctors completed questionnaires with a response rate of $81 \%$. Forty-eight were from the provincial hospital, 43 from county hospitals, and 111 from primary care facilities. The mean age was 35.2 $(\mathrm{SD}=7.6)$, and 105 doctors were male, with 85 female. Only $29 \%$ of primary care doctors had obtained a 5 -year formal medical education qualification compared with $93 \%$ and $96 \%$ at the county and provincial levels, respectively.

\section{Workload and pay}

The workload varied considerably with the level of the hospital. Provincial hospital doctors worked the longest hours; $60 \%$ routinely worked more than $60 \mathrm{~h} /$ week with $23 \%$ working more than $30 \mathrm{~h} /$ week in overtime (additional work hours and on a 'forced voluntary' basis largely due to heavy workload; table 2). For county level doctors, these figures were $47 \%$ and $9 \%$, and primary level doctors reported $21 \%$ and $2 \%$, respectively. Sixty-nine per cent of provincial hospital doctors saw over 50 patients in clinic per day with $46 \%$ seeing over
100 patients a day. There were $35 \%$ of doctors at secondary level facilities who saw over 50 outpatients per day and $33 \%$ at the primary level. Not surprisingly, consultation times were reported to be very short. Nearly $38 \%$ of provincial hospital doctors spent $4 \mathrm{~min}$ or less on average for each outpatient. This was in comparison with $14 \%$ in county hospitals, and $7 \%$ in primary care. Ninety per cent of doctors at the provincial hospital reported that they did on-call duties (which usually involved being available on site overnight to deal with referrals and problems), followed by the county level $(81 \%)$ and primary level (48\%). Eighty-seven per cent of provincial hospital doctors were required to do research in order to be eligible for promotion. This was in comparison with $42 \%$ and $28 \%$ in county level and primary care, respectively.

Remuneration consists of two parts: a basic salary and a bonus. For most doctors $(74 \%)$, their monthly salary was between 1000 and $3000 \mathrm{RMB}$ ( $1 \mathrm{USD}=6.16 \mathrm{RMB}$ in 2012 ), with only $1 \%$ paid more than 5000 RMB per month and 29\% paid between 3000 and 5000 RMB. Interestingly, $37 \%$ of county hospital doctors were paid less than 1000 RMB monthly and none of them earned over 3000 RMB. However, 19\% and 17\%, respectively, in primary care and tertiary hospitals were paid between $3000 \mathrm{RMB}$ and $5000 \mathrm{RMB}$. Up to $94 \%$ of junior doctors were paid $3000 \mathrm{RMB}$ or less, compared to $77 \%$ of middle-ranked doctors and $65 \%$ of senior doctors. Annual bonuses varied mainly by the level of the hospital: $79 \%$ in primary care, $91 \%$ in secondary hospitals and $38 \%$ in the tertiary hospital reported receiving $30000 \mathrm{RMB}$ or less. Half (51\%) in the tertiary hospital received a bonus between 30000 and $50000 \mathrm{RMB}$, while only $15 \%$ and $9 \%$, respectively, in primary and secondary hospitals earned this amount. Overall, only 12 doctors $(6 \%)$ reported receiving $50000 \mathrm{RMB}$ or more; seven of these were primary care doctors, five tertiary care doctors with none being county hospital doctors. Of those who did overtime, more than $80 \%$ were not paid for it.

\section{Job satisfaction}

Doctors' satisfaction with various aspects of work and conditions is shown in table 3 . Most striking are the differences between primary care physicians and doctors in higher-level hospitals (county and provincial hospitals). Very low proportions of high-level hospital doctors were satisfied with their working conditions: only $7 \%$ at highlevel hospitals were satisfied with their work hours, compared to $43 \%$ in primary care. Percentages for satisfaction with basic salary were $3 \%$ and $27 \%$, respectively, for higher level hospitals and primary care. Similar variations in bonuses were reported $(6 \%$ at higher level vs $20 \%$ in primary care). Less than $10 \%$ at high levels were satisfied with the amount of paid vacation time (3\%), amount of paid sick leave (5\%) and opportunities for promotion $(9 \%)$, compared with $38 \%, 41 \%$ and $25 \%$, respectively, in primary care. Interestingly, primary care 
Table 2 Characteristics of the sample and basic working conditions by level of hospital $\mathrm{n}(\%)$

\begin{tabular}{|c|c|c|c|c|c|}
\hline & \multirow[b]{2}{*}{$\begin{array}{l}\text { Total } \\
\mathrm{N}=202\end{array}$} & \multicolumn{3}{|c|}{ Level of hospital } & \multirow[b]{2}{*}{ p Value ( $\chi^{2}$ tests) } \\
\hline & & $\begin{array}{l}\text { CHCs } \\
\mathrm{N}=111\end{array}$ & County $N=43$ & $\begin{array}{l}\text { Provincial } \\
\mathrm{N}=48\end{array}$ & \\
\hline Age (mean and SD) & $35.2(7.6)$ & $36.1(8.6)$ & $34.2(7.4)$ & $34.0(4.1)$ & 0.196 \\
\hline Gender & & & & & 0.001 \\
\hline Male & $105(52.0)$ & $45(40.5)$ & $33(76.7)$ & $27(56.3)$ & \\
\hline Female & $85(42.1)$ & 59 (53.2) & $10(23.3)$ & $16(33.3)$ & \\
\hline Missing & $12(5.9)$ & $7(6.3)$ & 0 & $5(10.4)$ & \\
\hline Education level & & & & & 0.000 \\
\hline Postsecondary level or less & $78(38.6)$ & $75(67.6)$ & $3(7.0)$ & $0(0)$ & \\
\hline Undergraduate or higher & $118(58.4)$ & $32(28.8)$ & $40(93.0)$ & $46(95.8)$ & \\
\hline Missing & $6(3.0)$ & $4(3.6)$ & 0 & $2(4.2)$ & \\
\hline Position rank & & & & & 0.001 \\
\hline Low & $81(40.1)$ & $51(45.9)$ & $21(48.8)$ & $9(18.8)$ & \\
\hline Middle & $81(40.1)$ & $36(32.4)$ & $16(37.2)$ & $29(60.4)$ & \\
\hline High & $18(8.9)$ & $4(3.6)$ & $6(14.0)$ & $8(16.7)$ & \\
\hline Missing & $22(10.9)$ & $20(18.0)$ & 0 & $2(4.2)$ & \\
\hline Work hours/week & & & & & 0.000 \\
\hline$<40$ & $16(8.2)$ & $15(13.5)$ & 0 & $1(2.1)$ & \\
\hline $40-50$ & $60(30.6)$ & $42(37.8)$ & $13(30.2)$ & $5(10.4)$ & \\
\hline $50-60$ & $48(24.5)$ & $27(24.3)$ & $10(23.3)$ & $11(22.9)$ & \\
\hline$\geq 60$ & $72(36.7)$ & $23(20.7)$ & $20(46.5)$ & $29(60.4)$ & \\
\hline Missing & $6(3.0)$ & $4(3.6)$ & 0 & $2(4.2)$ & \\
\hline Outpatient visits per doctor per day & & & & & 0.000 \\
\hline$<50$ & $67(33.2)$ & $45(40.5)$ & $17(39.5)$ & $5(10.4)$ & \\
\hline $50-100$ & $58(28.7)$ & $34(30.6)$ & $13(30.2)$ & $11(22.9)$ & \\
\hline$\geq 100$ & $27(13.4)$ & $3(2.7)$ & $2(4.7)$ & $22(45.8)$ & \\
\hline Not applicable & $40(20.8)$ & $24(21.6)$ & $9(20.9)$ & $7(14.6)$ & \\
\hline Missing & $10(5.0)$ & $5(4.5)$ & $2(4.7)$ & $3(6.3)$ & \\
\hline Average visit time/patient (minutes) & & & & & 0.001 \\
\hline$\leq 4$ & $32(15.8)$ & $8(7.2)$ & $6(14.0)$ & $18(37.5)$ & \\
\hline$\overline{5}-9$ & $83(41.1)$ & $46(41.4)$ & $21(48.8)$ & $16(33.3)$ & \\
\hline $10-14$ & $31(15.3)$ & $18(16.2)$ & $8(18.6)$ & $5(10.4)$ & \\
\hline $15-20$ & $10(5.0)$ & $7(6.3)$ & $1(2.3)$ & $2(4.2)$ & \\
\hline$\geq 20$ & $5(2.5)$ & $4(3.6)$ & $1(2.3)$ & $0(0)$ & \\
\hline Not applicable & $33(16.3)$ & $24(21.6)$ & $4(9.3)$ & $5(10.4)$ & \\
\hline Missing & $8(4.0)$ & $4(3.6)$ & $2(4.7)$ & $2(4.2)$ & \\
\hline Overtime hours per week & & & & & 0.000 \\
\hline$<10$ & $103(51.0)$ & $69(62.2)$ & $23(53.5)$ & $11(22.9)$ & \\
\hline $10-30$ & $74(36.6)$ & $35(31.5)$ & $15(34.9)$ & $24(50.0)$ & \\
\hline$\geq 30$ & $17(8.4)$ & $2(1.8)$ & $4(9.3)$ & $11(22.9)$ & \\
\hline Missing & $8(4.0)$ & $5(4.5)$ & $1(2.3)$ & $2(4.2)$ & \\
\hline On-call duties & & & & & 0.000 \\
\hline Yes & $131(64.9)$ & $53(47.7)$ & $35(81.4)$ & $43(89.6)$ & \\
\hline No & $61(30.2)$ & $52(46.8)$ & $7(16.3)$ & $2(4.2)$ & \\
\hline Missing & $10(5.0)$ & $6(5.4)$ & $1(2.3)$ & $3(6.2)$ & \\
\hline Monthly salary & & & & & 0.000 \\
\hline$<1000 \mathrm{RMB}$ & $20(10.2)$ & $2(1.8)$ & $16(37.2)$ & $2(4.2)$ & \\
\hline $1000-3000$ RMB & $146(74.1)$ & $84(75.7)$ & $27(62.8)$ & $35(72.9)$ & \\
\hline $3000-5000$ RMB & $29(14.7)$ & $21(18.9)$ & 0 & $8(16.7)$ & \\
\hline$\geq 5000 \mathrm{RMB}$ & $2(1.0)$ & $1(0.9)$ & 0 & $1(2.1)$ & \\
\hline Missing & $5(2.5)$ & $3(2.7)$ & 0 & $2(4.2)$ & \\
\hline Total bonus last year (RMB) & & & & & 0.000 \\
\hline$<10000$ & $34(17.4)$ & $27(24.3)$ & $4(9.3)$ & $3(6.2)$ & \\
\hline $10000-30000$ & $106(54.4)$ & $57(51.4)$ & $35(81.4)$ & $14(29.1)$ & \\
\hline $30000-50000$ & $43(22.1)$ & $16(14.4)$ & $4(9.3)$ & $23(47.9)$ & \\
\hline $50000-100000$ & $9(4.6)$ & $7(6.3)$ & 0 & $2(4.2)$ & \\
\hline 100000 or higher & $3(1.5)$ & 0 & 0 & $3(6.3)$ & \\
\hline Missing & $7(3.5)$ & $4(3.6)$ & 0 & $3(6.3)$ & \\
\hline The need to do research & & & & & 0.000 \\
\hline Yes & $88(44.9)$ & $30(27.0)$ & $18(41.9)$ & $40(83.3)$ & \\
\hline No & $108(55.1)$ & $77(69.3)$ & $25(58.2)$ & $6(6.3)$ & \\
\hline Missing & $6(3.0)$ & $4(3.6)$ & 0 & $2(4.2)$ & \\
\hline
\end{tabular}


Table 3 Doctors' job satisfaction by level of hospital (\% of completely satisfied or satisfied)

\begin{tabular}{|c|c|c|c|c|c|c|}
\hline \multirow[b]{2}{*}{ Items } & \multirow[b]{2}{*}{$\begin{array}{l}\text { Satisfied } \\
\text { N (\%) }\end{array}$} & \multirow[b]{2}{*}{$\begin{array}{l}95 \% \mathrm{Cls} \text { of } \\
\text { percentages }\end{array}$} & \multicolumn{3}{|c|}{$\begin{array}{l}\text { Satisfied (\%) by level of } \\
\text { hospital }\end{array}$} & \multirow[b]{2}{*}{$\begin{array}{l}\text { p Value } \\
\left(\chi^{2} \text { tests }\right)\end{array}$} \\
\hline & & & $\begin{array}{l}\mathrm{CHCs} \\
(\mathrm{N}=111)\end{array}$ & $\begin{array}{l}\text { County } \\
(\mathrm{N}=43)\end{array}$ & $\begin{array}{l}\text { Provincial } \\
(\mathrm{N}=48)\end{array}$ & \\
\hline \multicolumn{7}{|l|}{ Work schedule and job reward } \\
\hline Hours of work & $52(25.7)$ & 20.2 to 32.2 & $46(42.6)$ & $2(4.7)$ & $4(8.30)$ & 0.000 \\
\hline Flexibility in scheduling & $47(23.3)$ & 18.0 to 29.6 & $38(35.5)$ & $5(11.6)$ & $4(8.30)$ & 0.000 \\
\hline Geographical location of work & $118(58.4)$ & 51.5 to 65.0 & $68(63.0)$ & $24(57.1)$ & $26(54.2)$ & 0.439 \\
\hline Basic salary & $32(15.8)$ & 11.5 to 21.5 & $29(27.4)$ & $0(0.0)$ & $3(6.3)$ & 0.000 \\
\hline Bonus & $26(12.9)$ & 8.9 to 18.2 & $21(20.0)$ & $3(7.0)$ & $2(4.2)$ & 0.000 \\
\hline Benefits (insurances, travelling, etc.) & $41(20.3)$ & 15.3 to 26.4 & $32(30.2)$ & $6(14.0)$ & $3(6.3)$ & 0.000 \\
\hline Amount of paid vacation time offered & $43(21.3)$ & 16.2 to 27.4 & 40 (37.7) & $1(2.3)$ & $2(4.2)$ & 0.000 \\
\hline Amount of paid sick leave offered & $48(23.8)$ & 18.4 to 30.1 & $43(41.0)$ & $3(7.0)$ & $2(4.2)$ & 0.000 \\
\hline Opportunities for promotion & $34(16.8)$ & 12.3 to 22.6 & $26(24.5)$ & $4(9.8)$ & $4(8.7)$ & 0.004 \\
\hline Job security & $94(46.5)$ & 39.8 to 53.4 & $55(50.9)$ & $15(36.6)$ & $24(51.1)$ & 0.536 \\
\hline Recognition for work by supervisors/senior staff & $113(55.9)$ & 49.1 to 62.6 & $65(60.2)$ & $22(52.4)$ & $26(55.3)$ & 0.742 \\
\hline Recognition in society & $87(43.1)$ & 36.4 to 50.0 & $63(58.3)$ & $10(23.3)$ & $14(29.2)$ & 0.000 \\
\hline \multicolumn{7}{|l|}{ Work relationships } \\
\hline Relationships with coworkers & $168(83.2)$ & 77.4 to 87.7 & $96(88.1)$ & $37(86.0)$ & 35 (72.9) & 0.116 \\
\hline Relationship(s) with supervisor(s) & $142(70.3)$ & 63.7 to 76.2 & 79 (75.2) & 35 (81.4) & $28(59.6)$ & 0.032 \\
\hline Relationships with subordinates & $150(74.3)$ & 67.8 to 79.8 & $85(86.7)$ & $32(80.0)$ & $33(73.3)$ & 0.247 \\
\hline Relationships with nurses & 168 (83.2) & 77.4 to 87.7 & 94 (86.2) & $38(88.4)$ & $36(75.0)$ & 0.271 \\
\hline \multicolumn{7}{|l|}{ Use and update of professional knowledge } \\
\hline $\begin{array}{l}\text { Opportunity to utilise your professional skills } \\
\text { and talents }\end{array}$ & $105(52.0)$ & 45.1 to 58.8 & $60(56.1)$ & $21(48.8)$ & $24(51.1)$ & 0.938 \\
\hline $\begin{array}{l}\text { Opportunity to learn new skills and new } \\
\text { knowledge }\end{array}$ & $83(41.1)$ & 34.5 to 48.0 & $42(38.9)$ & $16(37.2)$ & $25(52.1)$ & 0.573 \\
\hline Support for training and education & $87(43.1)$ & 36.4 to 50.0 & 49 (47.6) & 19 (44.2) & 19 (39.6) & 0.914 \\
\hline
\end{tabular}

doctors were most likely to feel they had high social recognition $(58 \%)$, compared with $29 \%$ at the provincial hospital and $23 \%$ at the county hospitals. Work relationships showed high levels of satisfaction across all health facilities. Levels of satisfaction with utilisation of expertise, opportunity to update expertise and support for training showed only small differences by level.

\section{Patients' help-seeking behaviours, demands and aggression}

Across all levels of facilities, doctors felt patients were becoming more demanding: $84 \%$ reported that patients often went to higher level hospitals for simple medical problems which could be solved at primary care facilities, whereas $80 \%$ said that patients just want to get drugs or tests rather than medical advice (table 4). Across all levels of facilities, doctors reported that patients were becoming more aggressive in their demands, with perceptions of high and increasing levels of complaints from patients, who are much more likely to sue than previously, with $87 \%$ reporting that there was an increasing trend of violence against doctors. County level doctors consistently reported higher levels for all these items.

\section{Influencing factors of job satisfaction}

Analysis comparing job satisfaction scores among subgroups, adjusted by gender, age and education, are presented in table 5. Doctors in the provincial hospital appeared to be the most dissatisfied group, and primary care physicians were most satisfied with their work $(p<0.001)$. Those who had worked longer hours $(p<0.001)$ did longer overtime hours $(p<0.05)$, took on-call duties $(\mathrm{p}<0.01)$ and were more likely to be dissatisfied. Doctors who reported average consultation times of 10-20 min per patient and a higher monthly salary showed higher satisfaction $(p<0.01)$. Doctors who had more negative perceptions of the doctor-patient relationship (thought the patients were more demanding and aggressive) also had lower satisfaction scores.

Finally, $88 \%$ (177) of the doctors said they would not want their children to be doctors. Of those 125 who provided a reason, $42(34 \%)$ said poor pay, $22(18 \%)$ said high pressure from work, and $21(17 \%)$ said it was a highrisk profession. Eleven $(9 \%)$ expressed concerns about personal insecurity or patient violence and conflicts, 11 (9\%) cited the poor doctor-patient relationship, and 17 $(14 \%)$ stated low status and social recognition.

\section{DISCUSSION}

This study provides some insights into the reasons for the low morale in the medical profession in China. Given the perceived low status, high perceived risk of violence and increasing litigation, it is perhaps not surprising that job satisfaction is low and that the 
Table 4 Patients' help-seeking behaviours, demands and aggression by level of hospital (\% of strongly agree or agree)

\begin{tabular}{|c|c|c|c|c|c|c|}
\hline \multirow[b]{2}{*}{ Items } & \multirow[b]{2}{*}{$\begin{array}{l}\text { Agree } \\
\mathrm{N}(\%)\end{array}$} & \multirow[b]{2}{*}{$\begin{array}{l}95 \% \text { Cls of } \\
\text { percentage }\end{array}$} & \multicolumn{3}{|c|}{ Agree (percent) } & \multirow[b]{2}{*}{$\begin{array}{l}\text { p Value } \\
\left(\chi^{2} \text { tests }\right)\end{array}$} \\
\hline & & & $\begin{array}{l}\text { CHCs } \\
(\mathrm{N}=111)\end{array}$ & $\begin{array}{l}\text { County } \\
(\mathrm{N}=43)\end{array}$ & $\begin{array}{l}\text { Provincial } \\
(\mathrm{N}=48)\end{array}$ & \\
\hline $\begin{array}{l}\text { Patients often go to higher level hospitals (eg, } \\
\text { tertiary hospitals) with simple complaints which } \\
\text { could be dealt with at a lower level hospital }\end{array}$ & $169(83.7)$ & 78.0 to 88.1 & $95(87.2)$ & $35(81.4)$ & $39(83.0)$ & 0.790 \\
\hline $\begin{array}{l}\text { Sometimes patients just want to get drugs and } \\
\text { tests rather than really seeking medical advice } \\
\text { from doctors }\end{array}$ & $162(80.2)$ & 74.2 to 85.1 & 84 (79.2) & 38 (88.4) & 40 (85.1) & 0.631 \\
\hline $\begin{array}{l}\text { Nowadays patients are better informed about } \\
\text { their own medical conditions so that sometimes } \\
\text { they demand specific treatments from doctors }\end{array}$ & 168 (83.2) & 77.4 to 87.7 & 93 (86.9) & 36 (85.7) & 39 (83.0) & 0.949 \\
\hline $\begin{array}{l}\text { Patients are becoming more aggressive in their } \\
\text { demands }\end{array}$ & 144 (71.3) & 64.7 to 77.1 & $66(60.6)$ & $40(93.0)$ & 38 (80.9) & 0.001 \\
\hline $\begin{array}{l}\text { The number of complaints by patients has } \\
\text { increased in recent years }\end{array}$ & $153(75.7)$ & 69.4 to 81.1 & 77 (72.6) & 41 (95.3) & 35 (72.9) & 0.006 \\
\hline $\begin{array}{l}\text { Patients are more likely to sue doctors even when } \\
\text { they are trying to do their best }\end{array}$ & $176(87.1)$ & 81.8 to 91.1 & $93(87.7)$ & $43(100.0)$ & 40 (83.3) & 0.107 \\
\hline $\begin{array}{l}\text { Violence against doctors by their own patients is } \\
\text { increasing }\end{array}$ & $176(87.1)$ & 81.8 to 91.1 & $92(86.8)$ & $43(100.0)$ & $41(85.4)$ & 0.126 \\
\hline
\end{tabular}

overwhelming majority of our sample (88\%) do not want their children to be doctors. Concerns for the future of the medical profession, and threats to the health system are being voiced quite openly even by senior Chinese authorities. ${ }^{31}$

Our findings highlight the causes of low job satisfaction among doctors. They also show that despite being the best qualified, and having the highest status and the highest income, doctors at the provincial hospital were the most dissatisfied group, followed by county hospital doctors with primary care doctors being the most satisfied. The causes of dissatisfaction fall into three main areas: low income, heavy workload and patient aggression. We will discuss these three factors together with the policy implications.

\section{Income}

Low income is a major grievance, mirroring findings in previous studies. ${ }^{28}{ }^{32}$ Even at the provincial level, $80 \%$ earned an annual salary of 36000 RMB or less. Among senior doctors, $35 \%$ earned more than this. This was in comparison with the average annual income of 34550 $\mathrm{RMB}$ in urban Zhejiang in 2012. ${ }^{33}$ While bonuses increase this considerably for some doctors, the overall income is still not regarded by most as sufficient compensation for the long hours and the risks incurred.

To better remunerate doctors, of course, demands more resources, but government investment in health remains insufficient. Total health expenditure remained under 5\% of GDP before the health reforms in 2009 and saw a slight increase to $5.36 \%$ in 2012 , compared to a GDP growth of $9.3 \%$ in 2011 and $7.8 \%$ in $2012 .{ }^{34} 35$ This compares with total health spending of around $10 \%$ of GDP in the UK, Germany, France, Norway, Canada and Japan. ${ }^{36}$ Government subsidy into these so-called public health facilities accounts for less than $10 \%$ of higher-level hospital revenue and $40 \%$ of community health centre revenue. ${ }^{37} 38$

Fees for basic medical services, including doctors' consultation, nursing services and surgical procedures, have been kept low ostensibly in order to ensure access to basic care for all. ${ }^{39}$ For example, in Beijing, ${ }^{40}$ a doctor consultation fee in an outpatient department is 2.5 RMB at a community health centre and $4 \mathrm{RMB}$ at a tertiary hospital. The staff costs (surgeons, nurses, anaesthetists) for an appendectomy are 150 RMB. These low costs are blamed in medical circles for the undervaluation of medical expertise. ${ }^{41}$ Since these charges are kept low, facilities operate a market system, making profits from prescribing drugs and tests. The health reforms were meant to address the problem of perverse incentives, partly through the introduction of the zero mark-up essential drug policy in 2009. The government started the policy in primary care level and it is now being rolled out in higher-level hospitals. With no mark-up from drugs now possible, the basic salary for the majority of doctors remains low. ${ }^{10} \mathrm{~A}$ series of experimental initiatives aiming to augment doctors' income are being launched, such as pay-for-performance and raising prices of services, including consultation fees and procedures. However, this may not fill the gap and doctors' income remains low. Some doctors are finding other ways to complement income. For example, a shift is being seen towards prescribing more Traditional Chinese Medicine.

Appropriate measures to address effort-reward imbalance must be taken. First, increasing government funding to increase doctors' salary can help to attract and retain good doctors. Second, increasing charges for healthcare may be useful to increase hospital revenue, 
Table 5 Influencing factors of doctors' job satisfaction controlling for gender, age and education

\begin{tabular}{|c|c|c|c|}
\hline \multirow[b]{2}{*}{ Variables } & \multicolumn{3}{|c|}{ Overall job satisfaction } \\
\hline & Mean & SD & p Value ${ }^{\star}$ \\
\hline \multicolumn{3}{|l|}{ Level of hospital } & 0.000 \\
\hline Primary (CHCs and THCs) & 3.23 & 0.06 & \\
\hline Secondary (county hospitals) & 2.83 & 0.08 & \\
\hline Tertiary (provincial hospital) & 2.82 & 0.09 & \\
\hline \multicolumn{3}{|l|}{ Position rank } & 0.064 \\
\hline Low & 3.12 & 0.06 & \\
\hline Middle & 2.91 & 0.06 & \\
\hline High & 2.97 & 0.15 & \\
\hline \multicolumn{3}{|l|}{ Work hours per week } & 0.000 \\
\hline$<50$ & 3.23 & 0.06 & \\
\hline 50 or more & 2.92 & 0.05 & \\
\hline \multicolumn{3}{|l|}{ Outpatient visits per doctor per day } & 0.102 \\
\hline$<50$ & 3.14 & 0.07 & \\
\hline $50-100$ & 2.99 & 0.07 & \\
\hline$\geq 100$ & 2.85 & 0.11 & \\
\hline Not applicable & 3.12 & 0.08 & \\
\hline \multicolumn{3}{|c|}{ Average visit time per patient (minutes) } & 0.004 \\
\hline$<10$ & 2.92 & 0.05 & \\
\hline $10-20$ & 3.23 & 0.08 & \\
\hline$\geq 20$ & 2.97 & 0.25 & \\
\hline Not applicable & 3.22 & 0.09 & \\
\hline \multicolumn{3}{|l|}{ Overtime hours per week } & 0.020 \\
\hline$<10$ & 3.15 & 0.05 & \\
\hline $10-30$ & 2.95 & 0.06 & \\
\hline$\geq 30$ & 2.83 & 0.13 & \\
\hline \multicolumn{3}{|l|}{ On-call duties } & 0.001 \\
\hline Yes & 2.94 & 0.05 & \\
\hline No & 3.26 & 0.08 & \\
\hline \multicolumn{3}{|l|}{ Monthly salary } & 0.004 \\
\hline$<1000 \mathrm{RMB}$ & 2.72 & 0.12 & \\
\hline $1000-3000$ RMB & 3.05 & 0.04 & \\
\hline$\geq 3000 \mathrm{RMB}$ & 3.24 & 0.10 & \\
\hline \multicolumn{4}{|c|}{ Patients' help-seeking behaviours and aggression } \\
\hline \multicolumn{3}{|c|}{$\begin{array}{l}\text { Patients often go to higher level hospitals (eg, tertiary hospitals) with simple complaints } \\
\text { which could be dealt with at a lower level hospital }\end{array}$} & 0.718 \\
\hline Disagree & 3.07 & 0.10 & \\
\hline Agree & 3.04 & 0.04 & \\
\hline \multicolumn{3}{|c|}{$\begin{array}{l}\text { Sometimes patients just want to get drugs and tests rather than really seeking medical } \\
\text { advice from doctors }\end{array}$} & 0.040 \\
\hline Disagree & 3.22 & 0.09 & \\
\hline Agree & 3.01 & 0.04 & \\
\hline \multicolumn{3}{|c|}{$\begin{array}{l}\text { Nowadays patients are better informed about their own medical conditions so that } \\
\text { sometimes they demand specific treatments from doctors }\end{array}$} & 0.586 \\
\hline Disagree & 2.99 & 0.11 & \\
\hline Agree & 3.05 & 0.04 & \\
\hline \multicolumn{3}{|c|}{ Patients are becoming more aggressive in their demands } & 0.008 \\
\hline Disagree & 3.22 & 0.08 & \\
\hline Agree & 2.98 & 0.04 & \\
\hline \multicolumn{3}{|c|}{ Patients are more likely to sue doctors even when they are trying to do their best } & 0.532 \\
\hline Disagree & 3.12 & 0.13 & \\
\hline & & 0.04 & \\
\hline \multicolumn{3}{|c|}{ The number of complaints by patients has increased in recent years } & 0.052 \\
\hline Disagree & 3.19 & 0.09 & \\
\hline & 3.00 & 0.04 & \\
\hline \multicolumn{3}{|c|}{ Violence against doctors by their own patients is increasing } & 0.063 \\
\hline Disagree & 3.27 & 0.13 & \\
\hline Agree & 3.02 & 0.04 & \\
\hline
\end{tabular}

* $p$ Values for analysis of covariance (ANCOVA) controlling gender, age and education. 
to reflect the value of doctors' expertise and to improve their self-value and morale. This increase should be covered by governmental insurance schemes. Third, involving doctors in proper evaluation and modifications of essential drug list policy is necessary, especially in deciding which drugs are on the list. There are known to be grievances about the content of the list and doctors want more autonomy in this regard. ${ }^{9}$ Also, it is important to note the socioeconomic disparities across China. It is extremely difficult to prescribe a national strategy, and exploration of local policies tailored to local socioeconomic conditions is warranted.

\section{Workload}

As long working hours appear to be a major contributor to dissatisfaction, especially at provincial and county hospitals, the huge volume of outpatients makes it difficult to spend sufficient time with patients, affecting the quality of care and the doctor-patient relationship. With no gatekeeping systems in primary care, many patients bypass lower levels to go to where they think they will get the best care, that is, provincial level hospitals. Inappropriate use of higher level care was commented on by $84 \%$ of our respondents. The health reform measures taken to strengthen primary care aimed partly to address this problem of massive overutilisation of secondary and tertiary facilities for mostly minor conditions. However, the reforms have probably made no difference. $^{9}$ This is because improvements in health insurance reimbursement have improved access, especially to higher-level facilities. Around $96 \%$ of the population now have health insurance. ${ }^{42}$ The outpatient throughput from 2009 to 2012 increased by $50 \%$ from 303 million to 455 million. ${ }^{43}$

With $46 \%$ of all outpatient consultations occurring at the county level and above in $2012,{ }^{44}$ the sheer volume of outpatient visits necessitates a very short consultation, inevitably jeopardising the quality of care. The health reforms have failed to discourage patients from inappropriately using higher-level care for minor conditions and this was a major goal of the reforms.

The discrepancy in workload and pressure between primary and higher level care partly explains the differences in job satisfaction. In primary care, doctors are not subject to the same pressures of long working hours, short and rushed consultations, and often unpaid overtime. In addition, primary care doctors mainly manage patients who are not seriously ill, and hence are less likely to be the target of patient complaints or aggression. To tackle the underlying problem of inappropriate use of higher level facilities, the primary care system needs to be further strengthened with the addition of a gate-keeping role. As we found in our study, primary care doctors have a much lower educational attainment, and this may contribute to the long-standing mistrust among the public. It has been 15 years since the introduction of community health services as a new primary healthcare model in urban areas. Despite the increasing government support, the general public still lack trust in these urban primary care physicians. ${ }^{45}$ The medical education curriculum needs to include more primary care and thus attract more well-qualified doctors into primary care. This would help to reduce patient flow to high level hospitals, and be far more cost-effective. However, the potential impact of a gate-keeping policy on primary care is not clear. Although it would make financial sense, a shift in workload to primary care may reduce job satisfaction for doctors at this level, creating new problems. A number of ongoing pilots in limited forms of gate-keeping $^{46}$ may provide some insights into the effects on job satisfaction across the three levels.

\section{Patient aggression}

Patients' aggressive demands and violence are having a serious impact on doctors' job satisfaction. ${ }^{11}{ }^{47}$ The situation is compounded by the fact that many of these violent events take place not only with impunity of the legal authorities, but also with the tolerance of the general public. In addition, while many receive scant media publicity, the internet spreads news of these events rapidly and widely. This has bred fears and insecurity, contributing to low morale in the profession. ${ }^{12}$

The causes of this patient aggression are complex. First, perverse incentives and doctors' profit-seeking behaviours have compromised quality of care, and led to erosion of professional ethics and higher medical costs. ${ }^{48}$ Certain areas of the media have taken to criticising doctors for their 'irresponsible and wrong' advice and occasional cases of extremely high medical expenses, which make patients feel exploited. ${ }^{49}$ In addition, patients are better informed about medical problems due to the increasingly accessible health information, leading them to be more demanding.

Second, in a commoditised healthcare system, despite the high coverage of medical insurance, patients are still paying a large portion of their medical expenses out of pocket. ${ }^{37}$ Together with the long waiting times and short consultation times, poor communication between doctors and patients can easily trigger tension between the two parties when doctors fail to meet patients' high expectations. Third, as doctors are the ones who dictate patient care, they are an easy target for patients' complaints and frustration.

Measures to prevent patient aggression against doctors are necessary. National measures to strengthen hospital security and criminalise any acts causing hospital disturbance were $\operatorname{taken}^{50}$ soon after a doctor was killed by a 17-year-old patient in 2012. However, these have been poorly enforced and critics argue that this does not solve the underlying systemic issues. More radical solutions are needed to prevent violence in health facilities. Policies of 'zero tolerance' towards violence in healthcare sectors are recommended by the most influential medical associations in China. ${ }^{51}$ However, the medical associations have no enforcement powers and are very rarely actually involved in medical disputes. Education 
programmes assisting doctors to prevent and manage patient violence may also be beneficial. ${ }^{52}$ An emphasis on doctor-patient communication skills in the medical school syllabus may help improve the doctor-patient relationship, and reduce patient aggression. ${ }^{53}$

\section{Limitations}

The study has some limitations. First, we sampled only four cities and counties in the province and only one provincial hospital. So the results have limited generalisability. The sample size was relatively small and doctors' participation was voluntary, leading to potential bias. However, we did sample across three levels of health institutions in four places with different economic levels. Second, as there are almost no studies on this topic, comparisons could not be made. Third, the job satisfaction score was developed for the paper and has not been formally validated. Nevertheless, it enabled us to compare the job satisfaction of doctors across different levels of hospital. However, as a first study comparing job satisfaction at three levels of facility and exploring associated systemic factors, we have provided a starting point for further research into exploring related issues in China.

\section{CONCLUSION}

Doctors in Zhejiang province, China have low job satisfaction overall. Measures must be taken to address this in order to address future problems of recruitment and retention of doctors. These measures must first include reduction of doctors' workload, especially at provincial hospitals, partly through incentivisation of appropriate utilisation of primary care, increase in doctors' salary and more punitive measures against individuals who commit violent acts against doctors. More research is needed to explore in depth the underlying causes of job satisfaction and discontent in Chinese doctors. There may be lessons from other countries and systems, where job satisfaction among doctors is generally high. ${ }^{54} 55$

\section{Author affiliations}

${ }^{1}$ Faculty of Medicine, Department of Family Medicine and Primary Care, The University of Hong Kong, Hong Kong, Hong Kong

${ }^{2}$ Faculty of Social Sciences, Centre for Suicide Research and Prevention, The University of Hong Kong, Hong Kong, Hong Kong

${ }^{3}$ Faculty of Science, Department of Statistics and Actuarial Science,

The University of Hong Kong, Hong Kong, Hong Kong

${ }^{4}$ UCL Institute of Global Health, University College London, London, UK

Acknowledgements The authors gratefully acknowledge Professor Yu Hai and Professor Du Ya Ping, Yu Di Di from the School of Medicine, Zhejiang University, Mao Li Nan from the Health Bureau of Zhejiang province, Zhou Peng Cheng from the Xiangya Hospital Central South University for their help during questionnaire development and data collection, and Professor Lam Tai Pong from the University of Hong Kong for his kind support during manuscript preparation.

Contributors TH and DW designed the study and the questionnaire. DW carried out the survey. KFL and YW performed the statistical analysis. DW, TH and YW interpreted the analysis. DW and TH drafted the manuscript. All authors read and approved the final manuscript.
Funding This research received no specific grant from any funding agency in the public, commercial or not-for-profit sectors.

\section{Competing interests None.}

Ethics approval Ethical approval was obtained from University College London. Local approvals were obtained from Zhejiang Health Bureau and local health authorities.

Provenance and peer review Not commissioned; externally peer reviewed.

Data sharing statement No additional data are available.

Open Access This is an Open Access article distributed in accordance with the Creative Commons Attribution Non Commercial (CC BY-NC 4.0) license, which permits others to distribute, remix, adapt, build upon this work noncommercially, and license their derivative works on different terms, provided the original work is properly cited and the use is non-commercial. See: http:// creativecommons.org/licenses/by-nc/4.0/

\section{REFERENCES}

1. Li D, Yin W, Zhang X, et al. Investigation on turnover intention of medical staff in public hospitals and research of early-warning system's construction. Chin J Hosp Adm 2010;26:218-21.

2. National Health and Family Planning Commission PRC. Research on relationship between Yi and Huan in China. Peking Union Medical College Press, 2008:106.

3. Wang ZG. Worrying conditions of doctors' practising environment: $78 \%$ of the doctors do not want their children to be doctors 2013. http://news.china.com.cn/2013-10/27/content_30414901.htm (accessed 3 Mar 2014).

4. Shanghai Jiao Tong University. Announcement of results of changing majors for students admitted in 2013. http://www.jwc.sjtu. edu.cn/web/sjtu/198015-1980000004584.htm (accessed 27 May 2014).

5. Flaherty $\mathrm{JH}$, Liu ML, Ding L, et al. China: the aging giant. $J A m$ Geriatr Soc 2007;55:1295-300.

6. CDC US. U.S. CDC IN CHINA: 2010-2011 Annual Report Healthy People in a Health China, 2013.

7. Song $\mathrm{K}$, Scott $\mathrm{A}$, Sivey $\mathrm{P}$, et al. Improving Chinese primary care providers' recruitment and retention: a discrete choice experiment. Health Policy Plan 2013. [Epub ahead of print 18 Dec 2013].

8. China Daily. WeChat poll revealed " $90 \%$ of participants do not want children to be doctors: high pressure and intense doctor-patient conflicts are main reasons". http://www.chinadaily.com.cn/ micro-reading/dzh/2014-04-23/content_11627822.html (accessed 23 May 2014).

9. Zhou XD, Li L, Hesketh T. Health system reform in rural China: voices of healthworkers and service-users. Soc Sci Med 2014;117:134-41

10. Guan XD, Liang HG, Xue YJ, et al. An analysis of China's national essential medicines policy. J Public Health Policy 2011;32:305-19.

11. Zhang $X$, Sleeboom-Faulkner M. Tensions between medical professionals and patients in mainland China. Camb Q Healthc Ethics 2011;20:458.

12. Hesketh T, Wu D, Mao LN, et al. Violence against doctors in China. Br Med J 2012;345:e5730.

13. Wang ZG. Yi Nao incidents increased by 7000 over last five years: illegal gangs made huge profits 2012. http://www.china.com.cn/ news/2012-05/03/content_25287333_2.htm (accessed 23 Jul 2014).

14. Xiong C. Medical malpractice and medical disputes. Chinese Hospital Association Guide, 2006.

15. Wu SY, Zhu W, Li HY, et al. Workplace violence and influencing factors among medical professionals in China. Am $J$ Ind Med 2012;55:1000-8.

16. Ding $X Y$. Chinese Hospital Association: violence against doctors gets worse. http://vote.dxy.cn/report/dxy/id/57914 (accessed 28 Feb 2014).

17. BMA. Violence at work: the experience of UK doctors. Health Policy and Economic Research Unit, British Medical Association, 2003.

18. Algwaiz WM, Alghanim SA. Violence exposure among health care professionals in Saudi public hospitals. A preliminary investigation. Saudi Med J 2012;33:76-82.

19. Behnam M, Tillotson RD, Davis SM, et al. Violence in the emergency department: a national survey of emergency medicine residents and attending physicians. J Emerg Med 2011;40:565-79.

20. Forrest LE, Herath PM, McRae IS, et al. A national survey of general practitioners' experiences of patient-initiated aggression in Australia. Med J Aus 2011;194:605-8. 
21. Joa TS, Morken T. Violence towards personnel in out-of-hours primary care: a cross-sectional study. Scand J Prim Health Care 2012;30:55-60.

22. Kowalenko T, Walters BL, Khare RK, et al. Workplace violence: a survey of emergency physicians in the state of Michigan. Ann Emerg Med 2005;46:142-7.

23. Magnavita N, Heponiemi T. Violence towards health care workers in a Public Health Care Facility in Italy: a repeated cross-sectional study. BMC Health Serv Res 2012;12:108.

24. Mirza NM, Amjad Al, Bhatti ABH, et al. Violence and abuse faced by junior physicians in the emergency department from patients and their caretakers: a nationwide study from Pakistan. J Emerg Med 2012:42:727-33.

25. Saeki K, Okamoto N, Tomioka K, et al. Work-related aggression and violence committed by patients and its psychological influence on doctors. J Occup Health 2011;53:356-64.

26. Sibbald B, Bojke C, Gravelle H. National survey of job satisfaction and retirement intentions among general practitioners in England. Br Med J 2003;326:22.

27. Liu JA, Wang Q, Lu ZX. Job satisfaction and its modeling among township health center employees: a quantitative study in poor rural China. BMC Health Serv Res 2010;10:115.

28. Shi L, Song K, Rane S, et al. Factors associated with job satisfaction by Chinese primary care providers. Prim Health Care Res Dev 2014;15:46-57.

29. Thakur M. Job satisfaction in banking: a study of private and public sector banks. The IUP J Bank Manag 2007;6:60-8.

30. Buciuniene I, Blazeviciene A, Bliudziute E. Health care reform and job satisfaction of primary health care physicians in Lithuania. BMC Fam Pract 2005;6:10

31. Ren Min Wang PRC. Liao Xin Bo: Improve doctors' dignity. http:// www.people.com.cn/n/2014/0213/c347759-24348138.htm (accessed 23 May 2014)

32. Lim M-K, Yang $\mathrm{H}$, Zhang T, et al. China's evolving health care market: how doctors feel and what they think. Health Policy 2004;69:329-37.

33. Zhejiang Provincial Bureau of Statistics. Statistical report on national economy and social development in Zhejiang Province. 2012. http:// tij.zj.gov.cn/tjgb/gmijshfzgb/201302/t20130208_122162.html (accessed 21 Feb 2014).

34. The World Bank. World Development Indicators: GDP growth (annual \%). http://data.worldbank.org/indicator/NY.GDP.MKTP.KD. ZG (accessed 7 Apr 2014)

35. National Health and Family Planning Commission PRC. Health statistics in China. 2012. http://www.moh.gov.cn/zwgkzt/ptity/201206/ 55044/files/3ca7756121334b7a870a25ac79988f23.pdf (accessed 7 Apr 2014).

36. The World Bank. Health expenditure, total (\% of GDP). 2012. http:// data.worldbank.org/indicator/SH.XPD.TOTL.ZS (accessed 24 May 2014).

37. National Health and Family Planning Commission PRC. China Health Statistics Yearbook. 2013. http://www.nhfpc.gov.cn/htmlfiles/ zwgkzt/ptjnj/year2013/index2013.html (accessed 23 May 2014).
38. Ren YJ, Ji QY. Analysis of salary distribution system in public hospitals. J Shanghai Jiaotong Univ 2013;33:712-16.

39. Yip W, Hsiao WC. The Chinese health system at a crossroads. Health Aff 2008;27:460-8.

40. Beijing Municipal Commission of Development and Reform. Prices of medical services in Beijing. http://service2.bjpc.gov.cn/bjpc/ mediprice/MedicalService1.jsp (accessed 28 Apr 2014).

41. Wang XH. Zhong Nan Shan: Chinese doctors survive by selling drugs and the value of their expertise is not being reflected. http:// news.xinhuanet.com/health/2014-03/06/c_126226620.htm (accessed 24 May 2014).

42. Meng Q, Xu L, Zhang Y, et al. Trends in access to health services and financial protection in China between 2003 and 2011: a cross-sectional study. Lancet 2012;379:805-14.

43. Health Bureau of Zhejiang Province. Health statistics in Zhejiang Province. http://www.zjwst.gov.cn/col/col320/index.html\#\#\# (accessed 31 Mar 2014).

44. Health Bureau of Zhejiang Province. Outpatient services in health facilities in Zhejiang Province. 2012. http://www.zjwst.gov.cn/art/ 2013/4/15/art_320 227356.html (accessed 31 Mar 2014)

45. Du J, Lu X, Wang $\bar{Y}$, et al. Mutual referral: a survey of GPs in Beijing. Fam Pract 2012;29:441-7.

46. Jia L, Ze Yong F. Dilemma of community first contact care. Chin Gen Pract 2012;15:720-2.

47. Yao Y, Wang W, Wang F, et al. General self-efficacy and the effect of hospital workplace violence on doctors' stress and job satisfaction in China. Int J Occup Med Environ Health 2014;27:1-11.

48. Yip WC-M, Hsiao W, Meng Q, et al. Realignment of incentives for health-care providers in China. Lancet 2010;375:1120-30.

49. Jie YX. 10 doctors calls for apologies from mass media about fasified reports. 2014. http://www.yxj.org.cn/news/yijieyaowen/ shehuijiaodian/2014052109582936651.htm (accessed 23 May 2014)

50. National Health and Family Planning Commission PRC. The directive of maintaining order at medical institutions by Police Department, Ministry of Health. http://wsb.moh.gov.cn/zwgkzt/ptg/ 201204/54578.shtml (accessed 11 Feb 2014).

51. CMA. United call for "Zero tolerance to medical violence" by Chinese Medical Association, Chinese Medical Doctor Association, Chinese Hospital Association and Chinese Health Law Society. http://www. cma.org.cn/index/xhdt/20131029/1383026180011_1.html (accessed 11 Feb 2014).

52. Zernike W, Sharpe P. Patient aggression in a general hospital setting: do nurses perceive it to be a problem? Int J Nurs Pract 1998;4:126-33.

53. Ong LM, De Haes JC, Hoos AM, et al. Doctor-patient communication: a review of the literature. Soc Sci Med 1995;40:903-18.

54. Aasland OG, Rosta J, Nylenna M. Health care reforms and job satisfaction among doctors in Norway. Scand J Public Health 2010;38:253-8.

55. Voltmer E, Rosta J, Siegrist J, et al. Job stress and job satisfaction of physicians in private practice: comparison of German and Norwegian physicians. Int Arch Occup Environ Health 2012;85:819-28. 